\title{
Integrative Therapy based on Yoga and Ayurveda for Treatment of a High-risk Case of COVID-19/SARS-Cov-2 with Multiple Co-morbidities
}

Alka Mishra*1 ${ }^{*}$ Sumitra A. Bentur ${ }^{\dagger 2}$, Sonika Thakral ${ }^{\ddagger 3,4}$, Rahul Garg $^{4}$, and Bhanu Duggal ${ }^{5}$

${ }^{1}$ Department of Ayurveda and Holistic Health, Dev Sanskriti Vishwavidyalaya, Haridwar, India

2 Ayurveda physician and yoga expert

${ }^{3}$ Shaheed Sukhdev College of Business Studies, University of Delhi, India

${ }^{4}$ National Resource Center for Value Education in Engineering, Indian Institute of Technology, Delhi, India

5 Department of Cardiology, All India Institute of Medical Sciences, Rishikesh, India

September 08, 2020

\begin{abstract}
Background: We report presumably the first known case of a high-risk COVID-19 positive patient with co-morbidities including Diabetes Mellitus (DM), Hypertension (HTN), Hypothyroidism and Chronic Kidney Disease (CKD), treated successfully using an Integrative Therapy plan based on Ayurveda and Yoga. Recently, some evidence has been emerging on the use of Ayurveda for treatment of COVID-19. The classical texts of Ayurvedic medicine such as Charaka Samhita and Sushruta Samhita contain the description of pandemics of similar proportions and describe them as Janapadoddhvansa meaning the destruction of communities, along with their causes and treatment.

Case Presentation: The reported case, a 55 year old male confirmed (tested) patient of COVID-19, who first took modern western medicine

*alka.mishra@dsvv.ac.in

†infobentursuma@yahoo.com

$\ddagger$ Corresponding author. sthakral@iitd.ac.in; sonika@sscbsdu.ac.in
\end{abstract}


(MWM) for 7 days before seeking the Integrative Therapy. The patient has comorbidities including DM, HTN, Hypothyroidism and CKD and had developed symptoms including fever (which was resolved by the time Integrative Therapy was started), sore throat, dry cough, body ache, weakness, bad taste and smell, and heaviness in abdomen. Based on the patient's symptoms and co-morbidities, a treatment plan including Ayurvedic medicines, Yoga protocol, dietary recommendations and lifestyle modifications was prescribed by a registered Ayurveda doctor and a Yoga consultant. The patient started experiencing improvement in all the symptoms within 2 days after starting the treatment; he reported approximately $75 \%$ relief from the symptoms after 5 days, and almost complete relief within 9 days. Also, the blood sugar levels (both Fasting Blood Sugar FBS, and Post Prandial Blood Sugar PPBS) exhibited significant improvement after 5 days, and came inside the normal range within 12 days. The patient was diagnosed free from infection on the basis of RT-PCR test on the $21^{\text {st }}$ day (sample taken on the $19^{\text {th }}$ day).

Conclusions: The Integrative Therapy was found effective in curing the COVID-19 patient with above-mentioned co-morbidities. Moreover, a significant improvement in blood sugar levels (not under control with modern medicine) was also achieved. Integrative Therapy based on classical texts of Ayurveda and Yoga may offer a promising and scalable treatment option for COVID-19 patients. A suitably designed randomized controlled trial is needed to assess its efficacy.

Keywords - SARS-Cov-2, COVID-19, Ayurveda, Yoga, Integrative Therapy

\section{Introduction}

The COVID-19 pandemic has wreaked havoc on every aspect of the human life on planet earth. As on August 28, 2020, more than 24.4 million cases of COVID-19 have been reported in more than 227 countries and territories, resulting in more than 8,31, 827 deaths [114]. Although there are several clinical trials under progress, no cure has yet been found for COVID-19 in the Modern Western Medicine (MWM).

The presence of co-morbidities such as Diabetes Mellitus (DM), Hypertention (HTN), Chronic Obstructive Pulmonary Disease (COPD) or old age leads to poorer clinical outcomes in COVID-19 patients $[28,111,98,118]$, and presents additional challenges in the management of the illness. The mortality rate for hospitalized COVID-19 patients in China has been reported to be $3.1 \%$ [28], while amongst these hospitalized patients, for those who have one or more of the nine co-morbidities (DM, HTN, COPD, Cardiovascular disease, Cerebrovascular disease, Hepatitis B infection, Malignancy, Chronic Kidney Disease CKD, Immunodeficiency), the mortality rate has been reported to be $8.8 \%$ [28]. In the same cohort, the percentage of patients for whom the illness progresses to a severe stage has been reported to be $16 \%$, whereas for patients with co-morbidities, the corresponding percentage is substantially higher at $32.8 \%$. Although the precise figures may vary with geography, the fact that presence of co-morbidities leads to poor clinical outcomes in COVID-19 patients has been independently confirmed in many studies from different countries [111, 98, 17, 19].

Ayurveda is a system of traditional Indian medicine, which is based on sound therapeutic principles and has a proven history of empirical use [64, 92]. It is one of the world's oldest holistic healing systems. As per Ayurvedic system of medicine, 
a healthy person is supposed to have a stable equilibrium (congenial homeostasis) of Doshas (Vata, Pitta, Kapha - psycho-biological rhythms), Agni (metabolism / digestion), Dhatu (body tissues/elements that provide them nourishment) and Mala (excreta), and the well being of senses, mind and soul [64]. Every individual has a unique combination of these constituent elements, which is known as the individual's Prakruti or unique mind-body constitution (Ashtanga Hridaya, Sharira Sthana, Chapter 3, Verse 83) [110]. When an imbalance occurs in this equilibrium, it is supposed to cause a disease, and the Ayurvedic system of medicine seeks to to remove this disbalance, to regain healthy state $[64,92]$.

The occurrence of disease can be further understood as follows: the above mentioned constituent elements have a propensity to change, influenced by various factors, such as the environment we live in, change in seasons, the food that is consumed, negative experiences, presence of physical toxins, irritants, micro-organism or impurities, unhealthy habits, emotions, etc. These influences distort the natural balance of these elements in an individual, increase ama (toxins), contributing to vikruti (vitiation of the constituent elements); this imbalance manifests as lack of energy, excess mucous, inflammation, and a wide variety of dysfunction and diseases [99, 64, 92]. By using the Ayurvedic principles, the unique Prakruti (constitution) of the individual is assessed, the vikruti (vitiation) that has occurred is diagnosed, and a personalized treatment plan is advised accordingly. Thus, the Ayurveda system of medicine is inherently personalized, which treats the patient by considering the individual constitution (Prakruti), as well as the causes of the symptoms (vikruti).

Classical Ayurveda texts such as Charaka Samhita (Vimana Sthana, Chapter 3) [92] and Sushruta Samhita (Sutra Sthana, Chapter 6, Verse 19, 20) [64], contain the description of pandemics and describe them as Janapadoddhvansa - Jana-pada (meaning community) + Udhvansa (meaning destruction), literally translating into 'destruction of communities'. These texts offer specific guidelines with regards to the treatment of diseases that affect people during Janapadoddhvansa.

Yoga is yet another ancient wisdom from India, which is an extremely deep science that helps one lead a harmonious life [108]. The classical text Yoga Vasishta [3] (Book 6 , Chapter 81) describes a healthy person as one who is free from physical disease as well as from erroneous affections of the mind. Yoga deals with the holistic principle of body-mind-soul, which proclaims that a human being can experience five dimensions of gross and subtle existence, called Pancha kosha or five sheaths, viz., Annamaya (physical body), Pranamaya (energy field), Manomaya (mental dimension), Vijnanamaya (related to intuitive knowledge) and Anandamaya (level of bliss) kosha (Taittiriya Upanishad) [94, 88]. Prana (the vital life force that is responsible for all the gross and subtle activities) pervades all these five sheaths, and nourishes and sustains them [88]. Yogic practices are aimed at achieving the proper distribution and circulation of Prana within the gross and subtle realms of existence, for holistic well-being.

Ayurveda also describes the concept of Panchaprana or Pancha Vayu (five manifestations of the vital life force in the human body) (Ashtanga Hridaya, Sutra Sthan, Chapter 12, Verse 4) [110]. Panchaprana govern different areas of the body and different physical, neurological and mental activities. When they are functioning harmoniously, they promote the health and vitality of the body and mind, and elevate one spiritually.

Thus, both Ayurveda and Yoga are powerful sciences that are aimed at the proper modulation of Prana in the human being, and when administered together in an integrative manner, these can be extremely effective with regards to restoring health, as well as managing or curing diseases. 
In this paper we report presumably the first high-risk case of COVID-19 (with reference to the studies available in peer reviewed open literature), treated successfully using Integrative Therapy comprising Ayurveda and Yoga. Although there have been some case reports (see the Section 2) and theoretical works on the use of Ayurveda or Yoga for COVID-19, the authors are not aware of any published work reporting the successful treatment of high-risk cases of COVID-19 through Ayurveda or Yoga. The present case offers a sufficiently supportive evidence that an Integrative Therapy plan based on Yoga and Ayurveda can be useful in treating even the high-risk cases of COVID-19 with mild to moderate symptoms. With regards to the work ahead, a suitably designed randomized control trial (RCT) would be advisable to further establish its efficacy for high-risk COVID-19 patients.

\section{Related Works}

There is emerging evidence that Ayurvedic treatment methodologies and herbal medicines may be effective in combating COVID-19. Girijaa and Sivan [23] describe one of the first case reports of a COVID-19 positive patient treated entirely with Ayurveda. Using molecular dynamics simulations, Kumar et al. [51] report that Withaferin-A (Wi-A), Withanone (Wi-N) derived from a common Ayurvedic herb called Ashwagandha, may block the entry of SARS-CoV-2 into cells. Several herbs such as Tulsi (Ocimum sanctum) and Haldi (Curcuma longa - turmeric) used as Ayurvedic medicines are well-known for their immunomodulatory properties [63, 40, 29, 84, 38]. Ayurvedic treatment has been also found to be effective in other COVID-like illnesses such as influenza [97, 93, 43], chikungunya [7]. Several studies have been conducted to understand the COVID-19 pandemic and the conditions posed by it from the perspective of Ayurveda $[77,46,68,22,76,101,60]$. Based on these observations and the study of classical Ayurveda texts, several experts have proposed the use of Ayurveda for prophylactic $[104,78,75,24,71,66,80,62,44,57,48,100,50,102]$ as well as therapeutic use $[83,75,73,109,105,24,71,66,62,21,44,39,49,101,72,85]$ in COVID-19. Some studies have also suggested that lifestyle modifications, such as immunity boosting food, can aid in fighting the current situation [4]. Many studies have come up with suggestions for reforms in policies enabling adoption of Ayurveda in the treatment plan for COVID-19 patients [90, 80, 1, 5]. Government of India, Ministry of AYUSH has issued an advisory comprising Ayurveda-based immunity boosting measures for self-care during COVID-19 crisis [61], and an advisory for general public on use of Ayurveda (and other traditional systems of medicines) as a preventive measure for COVID-19 as well as for managing the symptoms of COVID-19 [47]. The same department also issued guidelines for Ayurveda practitioners [25] and Yoga practitioners [26] for treating COVID-19 patients. Several clinical trials are ongoing for evaluating the efficacy of Ayurveda-based interventions for prophylactic as well as therapeutic use in mild to moderate patients of COVID-19.

Traditional Chinese medicine (TCM), which is based on principles similar to those of Ayurveda, has been extensively used in China for treating COVID-19. The Chinese Government actively promoted the use of TCM for management of COVID-19. As a result, several studies have been published on the use of TCM for COVID-19 [69, 112, 86, 113]. The Chinese doctors now recommend the use of TCM along with the western medicine in treating COVID-19 [42, 95]. According to [117] more than 85 percent of the cases in China have received TCM based treatment. Several randomized clinical trials (RCT) on TCM are presently under different stages of completion. Most of the 
reviews on RCTs on the efficacy of TCM for COVID-19 [70, 55, 8, 103, 18] report positive findings (see $[107,35]$ for reviews on mechanism of action of TCM). Several countries have issued guidelines for the use of traditional medicine for COVID-19. See $[116,2]$ for a review of such guidelines.

Despite the above studies on TCM, caution has also been advised in the use of TCM for COVID-19. For example, Gray and Belessis [27] state that the use of TCM may cause "more harm than good". Cyranoski [10] argues that TCM is still an unproven treatment and is being subjected to excessive promotion by certain governments. A review by Pang et al. [74] reported that after comprehensive literature search, they found 26 published clinical controlled trials of TCM for COVID-19, out of which 11 were RCTs with 1301 patients; however, none of the RCTs were placebo-controlled and double-blinded. There was significant variation in the types of patients, interventions and outcomes in different RCTs. Also, for most of the published trials, the protocols had not been registered before case recruitment. Thus, based on the above observations, it may be concluded that TCM may offer a promising option for treating COVID-19, yet suitably designed multi-country RCTs may be needed to assess its efficacy.

Promising results observed in several research studies are suggestive of favourable impact of Yoga on immune function, stress response, mental health and quality of life $[15,54,36,67,82,52]$. The usefulness of nasal irrigation, a yogic practice, in improving symptoms and health status of patients with sinonasal disease has also been observed [106]. A key symptom associated with COVID-19 is the onset of dyspnea between $4^{t h}$ and $10^{t h}$ day of illness [9]. Studies suggest that COVID-19 patients with hypoxia or dyspnea may have a higher risk of mortality or developing severe outcomes [96, 115]. It has been reported that a simple intervention such as prone positioning improves the clinical outcomes in such cases [16, 59]. Yoga and Pranayama have been found helpful in cases of high-altitude hypoxia [33], and several similar interventions in pulmonary rehabilitation for ARDS/COPD patients [56, 53, 30, 20, 12, 81, 31]. Therefore, it is hypothesized that Yoga and Pranayama can be of help in maintaining the oxygen saturation at safe levels in COVID-19 patients. Owing to its role in stress reduction and immune modulation, Yoga has been proposed as a complimentary therapy in the management of an infectious condition like COVID-19 [65]. Bushell et.al. [6] suggest Yoga practices and meditation as a potential adjunctive treatment for COVID-19. In light of the above observations, the present Integrative Therapy plan was designed, which comprises elements of Yoga and Ayurveda, along with dietary recommendations and lifestyle modifications, as a treatment option for COVID-19. It is hypothesized that the Integrative Therapy based on Ayurveda and Yoga would be effective in treating COVID-19 patients.

\section{Methods}

\subsection{Case Report}

A Delhi-based 55 year old male (confirmed positive) COVID-19 patient (height:5'3"; weight: approx. $70 \mathrm{Kg}$ ) filled in the online registration and consent forms on July 1, 2020 to receive Yoga and Ayurveda based Integrative Therapy via telemedicine. The Ayurveda doctor and the Yoga consultant talked to the patient over phone the same day for taking his medical history and symptoms pertaining to COVID-19, and prescribing Integrative Therapy based treatment. 


\subsubsection{History of the Present Illness}

The patient was asymptomatic three weeks prior to the first consultation for the Integrative Therapy. Later, he started developing symptoms of pneumonia, following which he was admitted to the hospital and underwent the RT-PCR test. The patient was detected positive on June 24, 2020. Subsequently, he was prescribed the following allopathic medication for 10 days - Nizonide 500mg (Nitazoxanide $500 \mathrm{mg}$ ), Doxy 100mg (Doxycycline 100mg), PAN 40mg (Pantoprazole 40mg), Vitamin C, MatildaER (Methylcobalamin, Pyridoxine and Folic acid), LCZ 5mg (Levocetirizine 5mg). On July 1, 2020, at the time of the first consultation for the Integrative Therapy, the patient was home quarantined.

\subsubsection{Complaints due to Present Illness}

\section{Resolved prior to the first consultation}

The patient had fever for about 10 days until June 22, 2020, after which he never had fever again. He also reported to have had dry cough and body-ache earlier, both of which no longer persisted at the time of his first consultation.

\section{Existing at the time of the first consultation}

The patient reported to be experiencing occasional obstruction in the throat while speaking for a substantial duration of time. He also felt weak due to which he sounded very low and lacking in energy. According to the patient's description, he used to get exhausted even on doing his own daily chores. The patient had heaviness in the abdomen (gastric upset) and often experienced a bloating feeling. Also, the patient had been having feelings of bad smell and taste, which occurred less frequently then as compared to earlier. The patient's appetite was reduced.

\subsubsection{Other Existing Illnesses/Comorbidities}

The patient was found to have the following comorbidities at the time of the first consultation. He had Diabetes Mellitus - Type II for the past 10 years and had been on allopathic medication (Glimepiride-2mg, Galvas-50mg, Vobit-0.3mg) for the same. However, despite regular use of the prescribed medicine, the illness was not very well controlled with the Fasting Blood Sugar mostly remaining more than $200 \mathrm{mg} / \mathrm{dl}$ and Post Parendial Blood Sugar more than $250 \mathrm{mg} / \mathrm{dl}$, as well as renal dysfunction (as evident in his reports dated June 23, 2020). The patient was also found to be hypertensive for the past 20 years, and had been on allopathic medication (Torcilin10); hypertension was under control with the medication. Hypothyroidism - since 22 years; taking allopathic medication (Thyroxin $75 \mathrm{mcg}$ ) and under control.

\subsubsection{History of Past Illnesses}

The patient had undergone Cholecystectomy (removal of gall bladder) 20 years ago.

\subsection{Ayurvedic Interpretation of the Patient's Condition}

\subsubsection{Diagnosis}

Based on the above history and discussion with the Ayurvedic Doctor and Yoga Consultant, it was understood that the patient had past medical history of Type II Di- 
abetes Mellitus (not well controlled), Hypertension, Hypothyroidism and CKD. The present illness started with fever, dry cough, weakness, and breathlessness, that led to his hospitalization, followed by diagnosis of pneumonia and positive test for COVID19. At the time of starting the present integrative treatment, the fever of the patient had been completely resolved, but he was still suffering from difficulty in speech, weakness, feeling of bad smell and taste, heaviness in abdomen (gas formation, distended abdomen), uneasiness in the body, and less appetite. The diagnosis of the patient's illness included COVID-19 positive, with Type II Diabetes Mellitus, Hypertension, Hypothyroidism and CKD.

\subsubsection{Pathophysiology}

As per Ayurvedic principles, since jwara (fever), shvasa (respiratory distress) and kasa (cough) are the three major symptoms of this roga (disease), hence the roga marga (pathway of disease) of this roga can be considered to be Abhyantara (internal origin) [23]. Since there is respiratory distress, along with other symptoms, hence there is Pranavaha Sroto Dushti (obstruction of the Pranavaha Srotas, i.e. the subtle microchannels in the body that are the pathways for the vital life force); also, one of the primary seat of this disease is Uras (chest region) [23]. Based on these observations, this disease can be characterized as Agantuja Sannipataja Jwara, wherein Vata-Kapha doshas are primarily vitiated [23].

In Agantuja Sannipataja Jwara, Agantuja implies Agantu (external), i.e. caused by Bhoota Abhishanga (external causative factors like virus); this in turn causes the vitiation of all the three Doshas, i.e. Vata, Pitta and Kapha [23]. Because of the vitiation of all the three Doshas, the term Sannipataja is used [23]. As per Ayurvedic principles, the treatment of such a Jwara is similar to that of Nija Jwara, i.e., the one caused by vitiation of Doshas [23].

\subsubsection{Etiology}

As per Ayurvedic principles, this disease can be correlated with Agantuja Sannipataja Jwara, wherein Vata-Kapha are primarily vitiated [23]. Furthermore, this is an extremely contagious disease, caused by Bhoota Abhishanga (external causative factors like virus), that is characterized in Ayurvedic texts as a Janapadoddhvansa disease [23, 64, 92]. Classical Ayurvedic texts like Charaka Samhita (Vimana Sthana - Chapter 3) [92] and Sushruta Samhita (Sutra Sthana - Chapter 6 - Verse 19,20) [64] contain the description of similar pandemics, and describe them as JanapadoddhvansaJanapada meaning community + Uddhvansa meaning destruction - literally translating into destruction of communities. The symptoms of illness during Janapadoddhvansa, as mentioned in classical texts, include cough, dyspnoea, asthma, vomiting, nasal catarrh (common cold), headache, fever, etc. [64]. These texts also offer specific guidelines with regards to the treatment of diseases that affect people during Janapadoddhvansa, which include Ayurvedic medicines, spiritual practices, etc. [92, 64].

\subsection{Therapeutic Intervention}

This section presents the detailed treatment plan along with justification for the same, as well as the details of the subsequent compliance of the patient. 


\subsubsection{Treatment Plan}

The following Ayurvedic medicines were prescribed: Giloy Ghanvati (3 doses of 2 tablets each to be taken after meal with lukewarm water), Ashwagandha vati (2 doses of 2 tablets each to be taken after meal), Pathyadi Kwath - pravahi (15 ml mixed with an equal quantity of lukewarm water to be consumed twice a day 30 minutes after meal), and Diabecon (2 doses of 1 tablet each to be taken 30 minutes before meal).

The Yoga protocol designed for the patient comprised Sukshma Vyayama (subtle joint movements for upper and lower body parts), breathing exercises (4 exercises with 5 iterations in each), asanas (Parshva Sukhasana, Sukhasana twist, Utthana Mandukasana, Ardha Ushtrasana, Meru Vakrasana, Ardha Halasana - with one leg folded, Anantasana, Pawan Muktasana), Shavasana, Pranayama (Sectional breathing and full Yogic breathing, Anulom-Vilom, Bhramari, Udgeet), and Dhyana (Mindful breathing). Online guided sessions were given for the first 14 days, thereafter a recrded video of the protocol (with verbal instructions and demonstration) was provided for the patient to be able to practise independently. Looking at the anxiety level of the patient, he was also suggested to practise Yoga Nidra [89] (guided Yogic sleep and relaxation practice), for which he was provided a link to guided audio instructions for Yoga Nidra (in Hindi language) by Swami Satyananda Saraswati; the duration of the practice being 42 minutes.

The patient was also recommended the following dietary and lifestyle modifications - beginning the day with Usha paan, i.e., drinking 2-3 glasses of lukewarm water, dietary intake of green vegetables, fruits, sprouts, barley, ragi flour, wheat porridge, sahajan (drumstick), roasted gram, methi (fenugreek), turmeric milk and dry fruits was suggested. Also, he was advised to refrain from cold, sour, fried, spicy or other food items that are heavy to digest; these included food items like curd, cold drinks, icecreams, chilled water, any refrigerated food items, black gram pulse (or any food item prepared with black gram), jackfruit etc. Besides the above dietary recommendations, the patient was encouraged to undertake spiritual practices such as meditation and chanting as per his linking and convenience, for which he was provided a link to the suggested spiritual practices [14].

\subsubsection{Justification for Ayurvedic Medicines}

Table 1 lists the detailed composition of the prescribed Ayurvedic medicines along with the botanical names of their ingredients. We next provide the justification for prescribing these medicines, based on the classical Ayurveda texts. 


\begin{tabular}{|c|c|}
\hline Common Name & Botanical Name \\
\hline \multicolumn{2}{|c|}{ Giloy Ghanvati } \\
\hline Giloy & Tinospora cordifolia \\
\hline \multicolumn{2}{|c|}{ Ashwagandha vati } \\
\hline Ashwagandha & "Withania somnifera \\
\hline \multicolumn{2}{|c|}{ Pathyadi Kwath (pravahi) [87] } \\
\hline Harad & Terminalia chebula \\
\hline Baheda & Terminalia bellerica \\
\hline Amla & Emblica officinalis \\
\hline Neem chhal & Azadirachta indica \\
\hline Giloy & Tinospora cordifolia \\
\hline Haldi & Curcuma longa \\
\hline \multicolumn{2}{|c|}{ Diabecon [32] } \\
\hline Shilajeet & "Asphaltum punjabinum \\
\hline Meshashringi/Gudmara/Madhunashini & Gymnema sylvestre \\
\hline Peetashala/Vijaysar/Indian Kino Tree & Pterocarpus marsupium \\
\hline \multicolumn{2}{|l|}{ Turmeric } \\
\hline Haldi & Curcuma longa \\
\hline
\end{tabular}

Table 1: Composition of Ayurvedic medicines

Giloy is known to have the following properties [91]: Tridosha shamaka (pacifies all the three doshas, i.e. Vata, Pitta, Kapha), Deepan Pachan (Rasa Dhatu, after proper metabolism, converts to the next Dhatu, i.e. Rakta or blood; undigested part of Rasa Dhatu acts as toxin, which is called Ama Dosha; this toxin is responsible for the blockage of micro-channels, i.e. srotas, leading to diseases; the Deepan Pachan property provides for enhancement of digestive fire for digestion of the Ama Dosha, thereby freeing the body of toxins), Jwaraghna (antipyretic), Pramehahara (anti-diabetic), Hrid-daurbalya nashak (useful in the treatment of heart problems), Yakrit vikar nashak (useful in the treatment of liver related problems), Kasa roga nashak (useful in the treatment of cough related problems), Raktashodhaka (blood purifier), and Rasayan (rejuvenating and removes weakness). Thus, these properties of Giloy (which is the sole ingredient of Giloy Ghanvati) justify its use in the management of various symptoms of COVID-19.

Ashwagandha has the following properties [91]: Kapha, Vata shamak (pacifies Kapha and Vata doshas), Balya (provides strength), Vringhan (nourishing effect), Rasayan (rejuvenating and removes weakness), Deepan (appetizer; and enhancer of the digestive fire), Anuloman (carminative, i.e., removes blockage in the gastro-intenstinal tract resulting in easy passage of Vata such as flatus), Shwasahara (helpful in cases of breathlessness or dyspnea), and mootral (dieuretic, i.e., helpful in kidney related problems). These properties justify the use of Ashwagandha vati for the presented case. 
The propeties of the ingredients of Pathyadi Kwath are as follows [87].

- Harad has the properties of [91]: Tridosha shamaka (pacifier of all the three doshas, i.e. Vata, Pitta, Kapha; especially useful in Vata disorders), Balya (strength providing), Medhya (nervine tonic), Deepan Pachan (enhances the digestive fire for digestion of the Ama Dosha, as described above), Yakrit uttejak (increases liver efficiency), Jwaraghna (antipyretic), Mootral (dieuretic, i.e., useful in kidney related problems), Anuloman (carminative, i.e., removes blockage in the gastro-intenstinal tract resulting in easy passage of Vata such as flatus) and Mridu-rechan (mild purgative).

- Baheda possesses the following properties [91]: Tridoshahara (pacifies all the three doshas, i.e. Vata, Pitta, Kapha, and is especially useful in Kapha disorders), Jwaraghna (antipyretic), Kasa roga nashak (treats cough related problems), Shwas roga nashak (helps in breathlessness, dyspnea), Swarabheda nashak (helps eliminate hoarseness of voice), Pratishyaya nashak (useful in common cold), Dhatuvardhak, (nourishes body tissues, especially Rasa - lymph, plasma, etc., Rakta or blood, Mansa or muscles, Meda or fat and Dhatus), Deepan (appetizer; and enhancer of the digestive fire), and Anuloman (carminative, i.e., removes blockage in the gastro-intenstinal tract resulting in easy passage of Vata such as flatus).

- Amla has the following properties [91]: Tridoshahara (pacifies all the three doshas, i.e. Vata, Pitta, Kapha; especially useful in Kapha disorders), Deepan (appetizer; and enhancer of the digestive fire), Anuloman (carminative, i.e., removes blockage in the gastro-intenstinal tract resulting in easy passage of Vata such as flatus), Rochan (removes anorexia, i.e., unwillingness to eat and reduced appetite), Rasayan (removes weakness and is rejuvenating), Balya (strength providing), Medhya (nervine tonic), Mootral (dieuretic), Jwaraghna (antipyretic), Pramehaghna (used to treat Madhumeha or diabetes), Yakrit uttejak (enhances liver efficiency), Kasa roga nashak (treats cough related problems), Shwas roga nashak (useful in breathlessness, dyspnea) and Hrid-roga nashak (used to treat heart problems).

- Neem chhal is known to have the following properties [91]: Kapha, Pitta shamak (pacifies Kapha and Pitta Doshas), Rochan (removes anorexia, i.e., unwillingness to eat or reduced appetite), Yakrit uttejak (enhances liver efficiency), Rakta shodhak (blood purifier), Prameha nashak (used to treat Madhumeha, i.e., diabetes), Ama pachak (digests the Ama Dosha, i.e. the toxins in the body, as described above under Giloy), Jwaraghna (antipyretic), Kasa roga nashak (used to treat cough related problems), and Dhatukshaya (prevents depletion of Dhatus).

- The properties of Haldi are as follows: Kapha, Vata shamak (pacifies Kapha and Vata Doshas), Pitta rechak (removes vitiated Pitta Dosha), extremely useful for Prameha (useful in disorders like diabetes), Ama pachak (digests the Ama Dosha, i.e. the toxins in the body, as described above under Giloy), Jwaraghna (antipyretic), Kasa roga nashak (used to treat cough related problems), Shwas roga nashak (useful in breathlessness, dyspnea), Anuloman (carminative, i.e., removes blockage in the gastro-intenstinal tract, resulting in easy passage of Vata such as flatus), and Rochak (removes anorexia, i.e., unwillingness to eat or reduced appetite),

- The properties of Giloy, another ingredient of Pathyadi Kwath, have been mentioned above under Giloy Ghanvati. 
Thus, the above ingredients of Pathyadi Kwath were expected to help the patient with the gastric issues he had been experiencing, resolve the bad taste and loss of appetite, enhance his digestion and rejuvenate him, remove weakness, as well as help in other symptoms of the disease.

The ingredients of the tablet Diabecon [32] have been discussed below. This was prescribed to address the not-well-controlled blood glucose levels of the patient.

- Shilajeet is known to possess the following properties [32, 41]: Vata, Pitta hara (pacifies Vata and Pitta Doshas), Rasayan (rejuvenates and removes weakness), Ama pachak (digests the Ama Dosha, i.e. the toxins in the body, as described above under Giloy), Kapha rog nashak (useful in Kapha related disorders), Mootra roga nashak (useful in urine related problems), useful in Prameha (useful in disorders like diabetes), Kasa roga nashak (used to treat cough related problems), and Shwas roga nashak (useful in breathlessness, dyspnea). It is also known to reduce hepatic glucose production, prevent hyperglycemia, protect b-cells of pancreas, and promote unrestricted endogenous insulin action [32].

- Meshashringi/Gudmara/Madhunashini has the following properties [32, 41]: Kapha, Vata shamak (pacifies Kapha and Vata Doshas), especially useful in Madhumeha (diabetes) - works by increasing the secretion of insulin and reducing the blood sugar level, Mootral (dieuretic, useful in kidney related problems), Madhurya nashak (removes the sweet taste of the tongue), Deepan (appetizer, enhances the digestive fire), Yakrit uttejak (enhances liver efficiency), Pratishyaya nashak (useful in common cold), Kasa roga nashak (used to treat cough related problems), and Shwas roga nashak (useful in breathlessness, dyspnea). The main constituent of Meshashringi is gymnemic acid that has anti-diabetic properties and reduces excess blood sugar; it also has a regenerative effect on the beta cells of pancreas and is insulinotropic, i.e. stimulates insulin's production and activity; it temporarily decreases sugar craving by removing the taste for sugar and enhances the activity of enzymes that are responsible for the absorption and utilization of glucose [32].

- Peetashala/Vijaysar/Indian Kino Tree has the properties of [32, 41]: Kapha, Pitta shamak (pacifies Kapha and Pitta Doshas), Madhumeha hara (useful in diabetes), Rasayan (rejuvenates and removes weakness), Rakta shodhak (blood purifier). It has the property of inhibiting alpha-glucosidase; it regularizes primary metabolic enzymes that are involved in carbohydrate metabolism [32].

The patient was also advised to consume turmeric milk, given the beneficial properties of haldi (given above).

\subsubsection{Justification for Yoga Protocol}

The Yoga component of the Integrative Therapy was designed to achieve maximum benefits considering the co-morbidities, COVID-19 symptoms and anxiety. The protocol began with Sukshma Vyayama (micro/subtle joints movements) that are preparatory practices to relieve joint stiffness and muscle tension, and also bring about relaxation. This was followed by breathing techniques, which improve the lung function, address weakness and reduce anxiety. Next in the protocol were Yogasanas (yogic postures) selectively picked to improve lung capacity and flexibility, enhance blood circulation, and bring about a deep sense of calmness. Postures involving intense 
backward bend were deliberately avoided since the patient has umbilical hernia. Following the asanas were relaxation techniques that counter stress response in the body. Stress raises blood glucose levels, suppresses the immune system, and increases blood pressure; relaxation techniques, such as Quick Relaxation Technique (QRT) [13], Deep Relaxation Technique (DRT) [13] and Yoga Nidra [89] are some powerful tools that reduce stress and anxiety. Given the anxiety and stress that the patient was undergoing, relaxation techniques were expected to bring about overall healing. The yoga sessions always concluded with Pranayama and Mindfulness meditation, which are known to reduce anxiety and improve lung function.

\subsubsection{Compliance}

Given below in Table 2 are the compliance details of the patient:

\begin{tabular}{|l|c|c|c|c|c|}
\hline & \multicolumn{5}{|c|}{ Intervention } \\
\hline Day & $\begin{array}{c}\text { Giloy } \\
\text { Ghanvati }\end{array}$ & $\begin{array}{c}\text { Ashwagandha } \\
\text { vati }\end{array}$ & $\begin{array}{c}\text { Pathyadi } \\
\text { Kadha }\end{array}$ & Diabecon & $\begin{array}{c}\text { Yoga+ } \\
\text { Pranayama }\end{array}$ \\
\hline \hline 1 & $\checkmark$ & $\checkmark$ & $\checkmark$ & $\checkmark$ & $\checkmark$ \\
\hline 2 & $\checkmark$ & $\checkmark$ & $\checkmark$ & $\checkmark$ & $\checkmark$ \\
\hline 3 & $\checkmark$ & $\checkmark$ & $\checkmark$ & $\checkmark$ & $\checkmark$ \\
\hline 4 & $\checkmark$ & $\checkmark$ & $\checkmark$ & $\checkmark$ & $\checkmark$ \\
\hline 5 & $\checkmark$ & $\checkmark$ & $\checkmark$ & $\checkmark$ & $\checkmark$ \\
\hline 6 & $\checkmark$ & $\checkmark$ & $\checkmark$ & $\checkmark$ & $\checkmark$ \\
\hline 7 & $\checkmark$ & $\checkmark$ & $\checkmark$ & $\checkmark$ & $\checkmark$ \\
\hline 8 & $\checkmark$ & $\checkmark$ & $\checkmark$ & $\checkmark$ & $\checkmark$ \\
\hline 9 & $\checkmark$ & $\checkmark$ & $\checkmark$ & $\checkmark$ & $\checkmark$ \\
\hline 10 & $\checkmark$ & $\checkmark$ & $\checkmark$ & $\checkmark$ & $\checkmark$ \\
\hline 11 & $\checkmark$ & $\checkmark$ & $\checkmark$ & $\checkmark$ & $\checkmark$ \\
\hline 12 & $\checkmark$ & $\checkmark$ & $\checkmark$ & $\checkmark$ & $\checkmark$ \\
\hline 13 & $\checkmark$ & $\checkmark$ & $\checkmark$ & $\checkmark$ & $\times$ \\
\hline 14 & $\checkmark$ & $\checkmark$ & $\checkmark$ & $\checkmark$ & $\checkmark$ \\
\hline 15 & $\checkmark$ & $\checkmark$ & $\checkmark$ & $\checkmark$ & $\checkmark$ \\
\hline 16 & $\checkmark$ & $\checkmark$ & $\checkmark$ & $\checkmark$ & $\checkmark$ \\
\hline 17 & $\checkmark$ & $\checkmark$ & $\checkmark$ & $\checkmark$ & $\times$ \\
\hline 18 & $\checkmark$ & $\checkmark$ & $\checkmark$ & $\checkmark$ & $\checkmark$ \\
\hline 19 & $\checkmark$ & $\checkmark$ & $\checkmark$ & $\checkmark$ & $\checkmark$ \\
\hline 20 & $\checkmark$ & $\checkmark$ & $\checkmark$ & $\checkmark$ & $\checkmark$ \\
\hline 21 & $\checkmark$ & $\checkmark$ & $\checkmark$ & $\checkmark$ & $\checkmark$ \\
\hline
\end{tabular}

Table 2: Compliance Chart

\section{Results}

The first consultation of the patient was done on the seventh day after the confirmation of COVID-19 through the RT-PCR test. He was under home-isolation during the entire course of treatment. All the symptoms reported by him were resolved by the ninth day after starting the treatment. However, since the report of the second RTPCR test received on the $8^{\text {th }}$ day of the treatment was positive, the intervention 
was continued (w.e.f. July 7, 2020) with slight modifications as reported in Section 4.1. The third RT-PCR report received on the $15^{\text {th }}$ day of the treatment (sample given on the $13^{\text {th }}$ day) was not conclusive, following which another test was done, whose report received on the $21^{\text {st }}$ day of the treatment (sample given on the $19^{\text {th }}$ day) showed no infection. Moreover, the patient's uncontrolled blood sugar level showed significant improvement, with FBS being $90 \mathrm{mg} / \mathrm{dl}$ and PPBS being $140 \mathrm{mg} / \mathrm{dl}$. Most importantly, the patient was in a much better state of mind (as evident through his feedback during consultations) and sounded much more confident by the end of the treatment.

\subsection{Timeline of COVID-19 Symptoms and Treatment}

A detailed description of the progress made by the patient and the medicines given during the course of the treatment is given below in Table 3.

\begin{tabular}{|c|c|c|c|c|c|}
\hline Day & Date & $\begin{array}{l}\text { FBS } \\
(\mathrm{mg} / \mathrm{dl})\end{array}$ & $\begin{array}{l}\text { PPBS } \\
(\mathrm{mg} / \mathrm{dl})\end{array}$ & Random & $\begin{array}{l}\text { Follow-up } \\
\text { details }\end{array}$ \\
\hline 0 & $1 / 7 / 2020$ & - & - & - & $\begin{array}{l}\text { Generally the blood sugar values } \\
\text { were like this - FBS }>200 \mathrm{mg} / \mathrm{dl} \text {, } \\
\text { PPBS }>250 \mathrm{mg} / \mathrm{dl} \text {, while the } \\
\text { patient had been taking allopathic } \\
\text { medication for the same; PPBS } \\
\text { was reported to be } 230 \mathrm{mg} / \mathrm{dl} \text { on } \\
30 / 6 / 2020 \text {. }\end{array}$ \\
\hline 1 & $2 / 7 / 2020$ & 192 & - & - & $\begin{array}{l}\text { Symptoms reported/observed: Diffi- } \\
\text { culty in speech, weakness, sometimes } \\
\text { feeling of bad smell and taste, heav- } \\
\text { iness in abdomen (due to gas for- } \\
\text { mation), uneasiness in body, less ap- } \\
\text { petite. }\end{array}$ \\
\hline 2 & $3 / 7 / 2020$ & 169 & - & - & $\begin{array}{l}\text { Improvement observed; approxi- } \\
\text { mately } 25 \% \text { relief reported in all the } \\
\text { symptoms; lightness in the body } \\
\text { reported. }\end{array}$ \\
\hline 3 & $4 / 7 / 2020$ & 190 & 206 & - & $\begin{array}{l}\text { Doing Yoga (twice daily); feeling } \\
\text { good, with improvement in all the } \\
\text { symptoms. }\end{array}$ \\
\hline 4 & $5 / 7 / 2020$ & 160 & 206 & - & $\begin{array}{l}\text { Approximately } 50 \% \text { relief reported in } \\
\text { all the symptoms; lightness in the } \\
\text { body reported. }\end{array}$ \\
\hline 5 & $6 / 7 / 2020$ & 155 & 175 & - & $\begin{array}{l}\text { No weakness; normal appetite; taste } \\
\text { and smell almost normal; approxi- } \\
\text { mately } 75 \% \text { relief reported. }\end{array}$ \\
\hline 6 & $7 / 7 / 2020$ & 140 & - & 110 & $\begin{array}{l}\text { No sore throat; no weakness; nor- } \\
\text { mal taste and smell; almost no other } \\
\text { problem except mild heaviness in ab- } \\
\text { domen; approximately } 80 \% \text { relief re- } \\
\text { ported. }\end{array}$ \\
\hline 7 & $8 / 7 / 2020$ & 140 & - & 110 & $\begin{array}{l}\text { No problem except mild heaviness in } \\
\text { abdomen. }\end{array}$ \\
\hline 8 & $9 / 7 / 2020$ & 130 & 230 & - & $\begin{array}{l}\text { Second RT-PCR report received on } \\
8 / 07 / 2020 \text { was +ve; slight change } \\
\text { done in the prescription: i) Diabecon } \\
-1 \text { tab. in the morning and } 2 \text { tab. } \\
\text { in the evening (earlier it was } 1 \text { tab. } \\
\text { in the evening) ii) advised to take } \\
\text { (ajwain }+ \text { saunf }+ \text { dhaniya) powder } \\
-1 / 2 \text { spoon, with lukewarm water, } \\
\text { after meal. }\end{array}$ \\
\hline 9 & $10 / 7 / 2020$ & 110 & 150 & - & $\begin{array}{l}\text { Improvement in all the problems (in- } \\
\text { cluding heaviness in abdomen) }\end{array}$ \\
\hline
\end{tabular}




\begin{tabular}{|c|c|c|c|c|c|}
\hline 10 & $11 / 7 / 2020$ & 110 & 150 & - & $\begin{array}{l}\text { No problem except mild heaviness in } \\
\text { abdomen; dose of Diabecon changed } \\
\text { to } 2 \text { tab. BD (patient advised } \\
\text { to start the revised dose from } \\
12 / 7 / 2020) \text {. }\end{array}$ \\
\hline 11 & $12 / 7 / 2020$ & 130 & 140 & - & $\begin{array}{l}\text { No problem except mild heaviness in } \\
\text { abdomen; started Diabecon } 2 \text { tab. } \\
\text { BD. }\end{array}$ \\
\hline 12 & $13 / 7 / 2020$ & 99 & 112 & - & $\begin{array}{l}\text { No problem except mild heaviness in } \\
\text { abdomen. }\end{array}$ \\
\hline 13 & $14 / 7 / 2020$ & 108 & 112 & - & $\begin{array}{l}\text { Sample given for RT-PCR test; no } \\
\text { problem except mild heaviness in ab- } \\
\text { domen. }\end{array}$ \\
\hline 14 & $15 / 7 / 2020$ & 120 & 165 & - & $\begin{array}{l}\text { No problem except mild heaviness in } \\
\text { abdomen. }\end{array}$ \\
\hline 15 & $16 / 7 / 2020$ & 108 & 140 & - & $\begin{array}{l}\text { RT-PCR test inconclusive as per the } \\
\text { report; no problem except mild heav- } \\
\text { iness in abdomen. }\end{array}$ \\
\hline 16 & $17 / 7 / 2020$ & 90 & 140 & - & $\begin{array}{l}\text { No problem except mild heaviness in } \\
\text { abdomen. }\end{array}$ \\
\hline 17 & $18 / 7 / 2020$ & & & & $\begin{array}{l}\text { No problem except mild heaviness in } \\
\text { abdomen. }\end{array}$ \\
\hline 18 & $19 / 7 / 2020$ & & & & $\begin{array}{l}\text { No problem except mild heaviness in } \\
\text { abdomen. }\end{array}$ \\
\hline 19 & $20 / 7 / 2020$ & & & & $\begin{array}{l}\text { Sample given for RT-PCR test; the } \\
\text { patient's allopathic doctor reduced } \\
\text { the dosage of his diabetes medica- } \\
\text { tion, i.e. Glimepiride changed from } 2 \\
\text { mg to } 1 \mathrm{mg} \text {; no problem except mild } \\
\text { heaviness in abdomen. }\end{array}$ \\
\hline 20 & $21 / 7 / 2020$ & & & & $\begin{array}{l}\text { Diabecon changed to Diabecon DS } 1 \\
\text { tab. BD; no problem except mild } \\
\text { heaviness in abdomen. }\end{array}$ \\
\hline 21 & $22 / 7 / 2020$ & & & & $\begin{array}{l}\text { RT-PCR reported no infection } \\
\text { (negative); no problem except mild } \\
\text { heaviness in abdomen. }\end{array}$ \\
\hline
\end{tabular}

\subsection{Followup}

Follow-up was done till August 01, 2020. The patient continued to report mild heaviness in the abdomen till July 26, 2020. Thereafter (w.e.f. July 27, 2020), he reported complete relief and rejuvenation. Besides the symptoms that appeared after being infected with the coronavirus, it was observed that the other ailments which the patient had a history of were also positively impacted. Table 4 summarizes the improvements observed in the reports of the patient received on August 14, 2020, as compared to those received on June 23, 2020; significant improvement can be seen in the values of HbA1c and Renal profile parameters. 


\begin{tabular}{|l|l|l|l|}
\hline & $\begin{array}{l}\text { June 23, } \\
2020\end{array}$ & $\begin{array}{l}\text { August 14, } \\
2020\end{array}$ & $\begin{array}{l}\text { Reference } \\
\text { Range }\end{array}$ \\
\hline \hline \multicolumn{3}{|c|}{ Blood Sugar } \\
\hline \multicolumn{3}{|c|}{ Renal Profile } \\
\hline Glycosylated Hb (HbA1c) & $9.2 \%$ & $6.6 \%$ & $<6.5 \%$ \\
\hline \hline $\begin{array}{l}\text { Blood Urea Nitrogen } \\
\text { (BUN) - Kinetic UV Test } \\
\text { (Urease, GLDH) }\end{array}$ & $30.4 \mathrm{mg} / \mathrm{dl}$ & $11.2 \mathrm{mg} / \mathrm{dl}$ & $\begin{array}{l}7.94 \mathrm{mg} / \mathrm{dl}- \\
20.09 \mathrm{mg} / \mathrm{dl}\end{array}$ \\
\hline $\begin{array}{l}\text { Creatinine - Kinetic Color } \\
\text { Test }\end{array}$ & $1.83 \mathrm{mg} / \mathrm{dl}$ & $0.75 \mathrm{mg} / \mathrm{dl}$ & $\begin{array}{l}0.67 \mathrm{mg} / \mathrm{dl}- \\
1.17 \mathrm{mg} / \mathrm{dl}\end{array}$ \\
\hline
\end{tabular}

Table 4: Follow-up details

\subsection{Patient's Perspective on the Treatment}

After recovery (dissolution of symptoms and negative RT-PCR report), a subjective feedback was taken from the patient to understand his perspective on the intervention. The patient expressed immense satisfaction and a sense of confidence. He was amazed and delighted to find that besides aiding in a speedy recovery from the symptoms of COVID-19, including weakness, anxiety and depression, Yoga and Ayurveda had managed to control his blood sugar level as well. The normal sugar levels observed by the end of the treatment were astounding given that regular allopathic medication could not achieve this. The patient was so convinced about the efficacy of Yoga and Ayurveda that he suggested his spouse (who was also tested positive for COVID-19 and had been pursuing only allopathic medication) to seek Ayurvedic consultation. Most importantly, he is determined to adopt Yoga in his lifestyle.

\section{An Accidental Control}

Coincidentally, a control case was found in the patient's family - his spouse, a 47 year old female who was tested positive for COVID-19 on the same date as the patient himself (June 24, 2020). She remained on allopathic medication ever since. On July 21, 2020, while our patient's report suggested that he was free from the infection, his spouse was still tested positive. It is worth emphasizing that while our patient had multiple comorbidities, his spouse had none. Even as late as July 10, 2020, she complained of symptoms like sputum (mild), sore throat (mild), bodyache, muscle cramps, weakness (mild), lower backache, disturbed sleep, anxiety with nervousness. On our patient's suggestion, she took Ayurvedic consultation and was advised medication on July 11, 2020. However, she was reluctant to take these medicines until July 22, 2020, when her COVID-19 test (RT-PCR) continued to report infection while our patient was reported free from infection. Finally, she started pursuing the prescribed Ayurvedic medicines on July 24, 2020, following which she was reported negative on July 31, 2020 in COVID-19 test (RT-PCR). 


\section{Discussion and Conclusions}

Besides the variety and severity of physiological symptoms posed by COVID-19, it deeply affects the patients psychologically as well $[34,58]$. Owing to the highly contagious nature of coronavirus, the social stigma associated with the disease and the involved isolation period have deep adverse impact on the already nervous patients [79]. This stress and anxiety may tend to further weaken the already compromised immune system, thereby potentially creating a vicious cycle. The patient treated in the presented case was undergoing a similar situation at the time of the first consultation. With his symptoms prevailing for long, and two more of his family members being infected (one of them being hospitalized), the patient was in severe distress and exhibited anxiety. The Integrative Therapy administered to him not only helped manage his physiological symptoms, but also helped control his anxiety and stress (see e.g., $[45,11]$ for reviews on Yoga for Anxiety). Within a week, an observable change in his confidence level was seen, and he appeared much more calm and peaceful. This change may be attributed to his regularity in attending the Yoga sessions, besides the relief experienced by subsiding of COVID-19 symptoms. The authors believe that apart from boosting immunity, Yoga and Pranayama practices immensely contributed to his overall healing by inducing a relaxation response [37] in the body. The success of the Integrative Therapy in this high-risk case of COVID-19 is evident in that the patient was not only cured of COVID-19, but a sense of overall well-being was bestowed on him.

This successfully treated case certainly calls for more well-designed studies on the proposed Integrative Therapy approach, possibly leading to its adoption in the standard treatment being provided to COVID-19 patients.

\section{Acknowledgements}

We would like to express sincere gratitude to Dr.Saurabh Mishra, Dev Sanskriti Vishwavidyalaya, for his continued guidance and valuable suggestions. We immensely benefitted from his all-rounded expertise. We also acknowledge the help and support extended by Prof. Bharat Bajirao Bhoyar, Chaudhary Brahma Prakash Ayurved Charak Sansthan.

\section{References}

[1] Amitava Acharyya. Prospect of Ayurveda System of Medicine in recent COVID19 Pandemic in India. International Journal of Ayurveda and Traditional Medicine, 2(2):26-29, 2020.

[2] Lin Ang, Hye Won Lee, Jun Yong Choi, Junhua Zhang, and Myeong Soo Lee. Herbal medicine and pattern identification for treating COVID-19: a rapid review of guidelines. Integrative Medicine Research, page 100407, 2020.

[3] Ravi Prakash Arya. The Yoga Vasistha of Valmiki. Chaukhamba Sanskrit Pratishthan, 2005.

[4] Swapan Banerjee, Saroj Srivastava, and Ashim Kumar Giri. Possible nutritional approach to cope with COVID-19 in Indian perspective. Advance Research Journal of Medical and Clinical Science, 6(06):207-219, 2020. 
[5] JL Berra, A Berra, et al. COVID-19 and Ayurveda in Argentina. Journal of Ayurveda Case Reports, 3(1):41, 2020.

[6] William Bushell, Ryan Castle, Michelle A Williams, Kimberly C Brouwer, Rudolph E Tanzi, Deepak Chopra, and Paul J Mills. Meditation and Yoga Practices as Potential Adjunctive Treatment of SARS-CoV-2 Infection and COVID19: A Brief Overview of Key Subjects. The Journal of Alternative and Complementary Medicine, 26(7):547-556, 2020.

[7] Central Council for Research in Ayurveda and Siddha, Department of AYUSH, Ministry of Health and Family Welfare, Government of India. Management of Chikungunya Through Ayurveda and Siddha: A Technical Report, 2009. Retrieved August 11, 2020 from http://www.ccras.nic.in/sites/default/files/22092016_MANAGEMENT $\% 20$ OF $\%$ 20CHIKUNGUNYA \%20THROUGH $\%$ 20AYURVEDA $\% 20$ AND $\% 20$ SIDDHA-\%20TECHNICAL\%20REPORT.pdf.

[8] Kam Wa Chan, Vivian Taam Wong, and Sydney Chi Wai Tang. COVID-19: An Update on the Epidemiological, Clinical, Preventive and Therapeutic Evidence and Guidelines of Integrative Chinese-Western Medicine for the Management of 2019 Novel Coronavirus Disease. The American journal of Chinese medicine, 48(03):737-762, 2020.

[9] Pieter A Cohen, Lara Hall, Janice N John, Alison B Rapoport, et al. The Early Natural History of SARS-CoV-2 Infection: Clinical Observations From an Urban, Ambulatory COVID-19 Clinic. Mayo Clinic Proceedings, 95(6):1124$1126,2020$.

[10] D Cyranoski. China is promoting coronavirus treatments based on unproven traditional medicines. Nature, 2020.

[11] Tricia L Da Silva, Lakshmi N Ravindran, and Arun V Ravindran. Yoga in the treatment of mood and anxiety disorders: A review. Asian Journal of Psychiatry, 2(1):6-16, 2009.

[12] DorAnne Donesky-Cuenco, Huong Q Nguyen, Steven Paul, and Virginia Carrieri-Kohlman. Yoga Therapy Decreases Dyspnea-Related Distress and Improves Functional Performance in People with Chronic Obstructive Pulmonary Disease: A Pilot Study. The Journal of Alternative and Complementary Medicine, 15(3):225-234, 2009.

[13] Dr. R Nagarathna Dr. H R Nagendra. New Perspectives In Stress Management. Swami Vivekananda Yoga Prakashana, June 1986.

[14] DSVV. Spiritual Practices Recommended during Present Times, 2020. Department of Ayurveda and Holistic Health. Dev Sanskriti Vishwavidyalaya, Haridwar. Retrieved August 26, 2020 from https://sites.google.com/dsvv.ac.in/dahh$\mathrm{dsvv} /$ notices/spiritual-practices-present-times.

[15] Nobuhiko Eda, Kazuhiro Shimizu, Satomi Suzuki, Yoko Tanabe, Eunjae Lee, and Takao Akama. Effects of yoga exercise on salivary beta-defensin 2. European Journal of Applied Physiology, 113(10):2621-2627, 2013.

[16] Xavier Elharrar, Youssef Trigui, Anne-Marie Dols, François Touchon, Stéphanie Martinez, Eloi Prud'homme, and Laurent Papazian. Use of Prone Positioning in Nonintubated Patients With COVID-19 and Hypoxemic Acute Respiratory Failure. Jama, 2020. 
[17] Omar Ariel Espinosa, Andernice dos Santos Zanetti, Ednardo Fornanciari Antunes, Fabiana Gulin Longhi, Tatiane Amorim de Matos, and Paula Franciene Battaglini. Prevalence of comorbidities in patients and mortality cases affected by SARS-CoV2: a systematic review and meta-analysis. Revista do Instituto de Medicina Tropical de São Paulo, 62, 2020.

[18] Arthur Yin Fan, Sherman Gu, Sarah Faggert Alemi, et al. Chinese herbal medicine for COVID-19: Current evidence with systematic review and metaanalysis. Journal of Integrative Medicine, page 1, 2020.

[19] Richard Franki. Comorbidities Increase COVID-19 Deaths by Factor of 12, 2020. Medscape. Retrieved August 12, 2020 from https://www.medscape.com/viewarticle/932486.

[20] Ashok Fulambarker, Basheeruddin Farooki, Fayez Kheir, Ahmet Sinan Copur, Lavanya Srinivasan, and Stephen Schultz. Effect of Yoga in Chronic Obstructive Pulmonary Disease. American Journal of Therapeutics, 19(2):96-100, 2012.

[21] Abhay Jayprakash Gandhi, Jalpa Deepak Rupareliya, VJ Shukla, Shilpa B Donga, and Rabinarayan Acharya. An Ayurvedic Perspective along with in Silico Study of the Drugs for the Management of Sars-Cov-2. Journal of Ayurveda and Integrative Medicine, 2020.

[22] Gunjan Garg. COVID-19 Pandemic: The Ayurvedic Perspective. International Journal of Ayurveda and Traditional Medicine, 2(2):1-2, 2020.

[23] PLT Girija and Nithya Sivan. Ayurvedic treatment of COVID-19/SARS-CoV-2: A case report. Journal of Ayurveda and Integrative Medicine, 2020.

[24] Sai Sailesh Kumar Goothy, Srilatha Goothy, Anita Choudhary, GG Potey, Hirok Chakraborty, Arun HS Kumar, and VK Mahadik. Ayurveda's Holistic Lifestyle Approach for the Management of Coronavirus disease (COVID-19): Possible Role of Tulsi. International Journal of Research in Pharmaceutical Sciences, 11(SPL1):16-18, 2020.

[25] Government of India, Ministry of AYUSH. Guidelines for Ayurveda Practitioners for COVID 19. Retrieved August 11, 2020 from https://www.ayush.gov.in/docs/ayurved-guidlines.pdf.

[26] Government of India, Ministry of AYUSH. Guidelines for Yoga Practitioners for COVID 19. Retrieved August 11, 2020 from https://www.ayush.gov.in/docs/yoga-guidelines.pdf.

[27] Paul E Gray and Yvonne Belessis. The use of Traditional Chinese Medicines to treat SARS-CoV-2 may cause more harm than good. Pharmacological research, 156:104776, 2020.

[28] Wei-jie Guan, Wen-hua Liang, Yi Zhao, Heng-rui Liang, Zi-sheng Chen, Yi-min Li, Xiao-qing Liu, Ru-chong Chen, Chun-li Tang, Tao Wang, et al. Comorbidity and its impact on 1590 patients with Covid-19 in China: a nationwide analysis. European Respiratory Journal, 55(5), 2020.

[29] Sai Krishna Gudi, Bhavani Ramesh.T, and Prem Kumar. "Tulsi" - the Wonder Herb (Pharmacological Activities of Ocimum Sanctum). American Journal of Ethnomedicine, 1:089-095, 022014.

[30] Randeep Guleria, Sneh Arora, Anant Mohan, Guresh Kumar, and Ajit Kumar. Yoga Is as Effective as Standard Pulmonary Rehabilitation in Improving Dyspnea, Inflammatory Markers, and Quality of Life in Patients With COPD. Chest, 148(4):907A, 2015. 
[31] Anupama Gupta, Rajesh Gupta, Sushma Sood, and Mohammad Arkham. Pranayam for Treatment of Chronic Obstructive Pulmonary Disease: Results From a Randomized, Controlled Trial. Integrative Medicine: A Clinician's Journal, 13(1):26, 2014.

[32] Himalaya. Diabecon. Retrieved August 8, 2020 from https://himalayawellness.in/products/diabecon.

[33] Gidugu Himashree, Latika Mohan, and Yogesh Singh. Yoga Practice Improves Physiological and Biochemical Status at High Altitudes: A Prospective Casecontrol Study. Alternative Therapies, 22(5):53-9, 2016.

[34] Yeen Huang and Ning Zhao. Generalized anxiety disorder, depressive symptoms and sleep quality during COVID-19 outbreak in China: a web-based crosssectional survey. Psychiatry Research, page 112954, 2020.

[35] Yu-Feng Huang, Chen Bai, Fan He, Ying Xie, and Hua Zhou. Review on the potential action mechanisms of Chinese medicines in treating Coronavirus Disease 2019 (COVID-19). Pharmacological Research, 2020.

[36] Infante, Jose R and Peran, Fernando and Rayo, Juan I and Serrano, Justo and Dominguez, Maria L and Garcia, Lucia and Duran, Carmen and Roldan, Ana. Levels of immune cells in transcendental meditation practitioners. International Journal of Yoga, 7(2):147, 2014.

[37] Gregg D Jacobs. Clinical Applications of the Relaxation Response and MindBody Interventions. The Journal of Alternative \& Complementary Medicine, 7(1):93-101, 2001.

[38] Ganesh Chandra Jagetia and Bharat B Aggarwal. "Spicing Up" of the Immune System by Curcumin. Journal of Clinical Immunology, 27(1):19-35, 2007.

[39] Rachana Jajal and Vijay Dive. Probable Protocol for Clinical Management of COVID-19 With Ayurvedic Treatment Modalities Adjuvant to Ongoing Conventional Treatment - A Review. International Journal of Research in Ayurveda and Medical Sciences, 3:132-137, 2020.

[40] Negar Jamshidi and Marc M Cohen. The Clinical Efficacy and Safety of Tulsi in Humans: A Systematic Review of the Literature. Evidence-Based Complementary and Alternative Medicine, 2017, 2017.

[41] Chandra Bhushan Jha. Ayurvediya Rasashastra. Varanasi, India: Chaukhambha Surabharati Prakashan, 2000.

[42] Ying-Hui Jin, Lin Cai, Zhen-Shun Cheng, Hong Cheng, Tong Deng, Yi-Pin Fan, Cheng Fang, Di Huang, Lu-Qi Huang, Qiao Huang, et al. A rapid advice guideline for the diagnosis and treatment of 2019 novel coronavirus (2019-ncov) infected pneumonia (standard version). Military Medical Research, 7(1):4, 2020.

[43] Gayatri S Kalamkar, RV Sawai, and MV Rampurkar. Role of Ayurveda in Communicable Diseases. International Journal of Ayurvedic Medicine, 6(1):28$31,2015$.

[44] Sarbeswar Kar, B Gurubasavaraja, S Vikaram, KV Sriharsha, and Ranjani Deshpande. Ayurvedic Preventive and Curative Protocol for COVID 19-A Proposal. Journal of Ayurveda and Integrated Medical Sciences (ISSN 2456-3110), 5(2):92$108,2020$. 
[45] Graham Kirkwood, Hagen Rampes, Veronica Tuffrey, Janet Richardson, and Karen Pilkington. Yoga for anxiety: a systematic review of the research evidence. British Journal of Sports Medicine, 39(12):884-891, 2005.

[46] V Kirthana, B Venkataiah, MR Narayana Murthy, et al. COVID 19 in ayurvedic perspective. International Journal of Health \& Allied Sciences, 9(5):91, 2020.

[47] Vaidya Rajesh Kotecha. Advisory From Ministry of AYUSH for Meeting the Challenge Arising Out of Spread of Corona Virus (COVID-19) in India, March 6, 2020. Secretary, Ministry of AYUSH, Government of India. Retrieved August 11, 2020 from https://www.ayush.gov.in/docs/125.pdf.

[48] Girish Ashok Kulkarni. CONCEPTUAL STUDY OF AAHARA VIDHI VISHESHA AYATANA IN PANDEMIC DISEASE COVID-19. Journal of Ayurveda and Integrated Medical Sciences (ISSN 2456-3110), 5(3):75-79, 2020.

[49] Abhimanyu Kumar, Govind Prasad, Sanjay Srivastav, Vinod Kumar Gautam, and Neha Sharma. A Retrospective Study on Efficacy and Safety of Guduchi Ghan Vati for Covid-19 Asymptomatic Patients. medRxiv, 2020.

[50] Vijay Kumar, Shyam Babu Singh, and Simranjeet Singh. COVID-19: Environment concern and impact of Indian medicinal system. Journal of Environmental Chemical Engineering, 8(5):104144, 2020.

[51] Vipul Kumar, Jaspreet Kaur Dhanjal, Priyanshu Bhargava, Ashish Kaul, Jia Wang, Huayue Zhang, Sunil C Kaul, Renu Wadhwa, and Durai Sundar. Withanone and Withaferin-A are predicted to interact with transmembrane protease serine 2 (TMPRSS2) and block entry of SARS-CoV-2 into cells. Journal of Biomolecular Structure and Dynamics, 0(just-accepted):1-27, 2020.

[52] NIDN Kusnanto, Joni Haryanto, Tintin Sukartini, Elida Ulfiana, Made Mahaguna Putra, et al. The Effectiveness of Spiritual Emotional Breathing Towards Respiratory Function and Immune Response of Tuberculosis Patients. Jurnal Ners, 13(1):93-97, 2018.

[53] Chenyang Li, Yanhui Liu, Yunan Ji, Lingli Xie, and Zhenhua Hou. Efficacy of yoga training in chronic obstructive pulmonary disease patients: A systematic review and meta-analysis. Complementary Therapies in Clinical Practice, 30:33$37,2018$.

[54] Sung-Ah Lim and Kwang-Jo Cheong. Regular Yoga Practice Improves Antioxidant Status, Immune Function, and Stress Hormone Releases in Young Healthy People: A Randomized, Double-Blind, Controlled Pilot Study. The Journal of Alternative and Complementary Medicine, 21(9):530-538, 2015.

[55] Ming Liu, Ya Gao, Yuan Yuan, Kelu Yang, Shuzhen Shi, Junhua Zhang, and Jinhui Tian. Efficacy and Safety of Integrated Traditional Chinese and Western Medicine for Corona Virus Disease 2019 (COVID-19): a systematic review and meta-analysis. Pharmacological Research, page 104896, 2020.

[56] Xun-Chao Liu, Lei Pan, Qing Hu, Wei-Ping Dong, Jun-Hong Yan, and Liang Dong. Effects of yoga training in patients with chronic obstructive pulmonary disease: a systematic review and meta-analysis. Journal of Thoracic Disease, 6(6):795, 2014.

[57] Agnibha Das Majumdar, Vijay Mohan Soni, and Neha Munjal. Ayurveda and Yoga: An Immunity Booster at the Time of COVID-19 Pandemic. International Journal of Research in Engineering, Science and Management, 3(6), 2020. 
[58] Mario Gennaro Mazza, Rebecca De Lorenzo, Caterina Conte, Sara Poletti, Benedetta Vai, Irene Bollettini, Elisa Maria Teresa Melloni, Roberto Furlan, Fabio Ciceri, Patrizia Rovere-Querini, et al. Anxiety and depression in COVID19 survivors: Role of inflammatory and clinical predictors. Brain, Behavior, and Immunity, 2020.

[59] Bairbre McNicholas, David Cosgrave, Camilla Giacomini, Aoife Brennan, and John G Laffey. Prone positioning in COVID-19 acute respiratory failure: just do it? British Journal of Anaesthesia, 2020.

[60] Kundan Rameshwar Meshram et al. Critical Review on COVID-19 in Perspective of Ayurveda and Its Legal \& Psychological Backgrounds. IJRAR-International Journal of Research and Analytical Reviews (IJRAR), 7(2):424-435, 2020.

[61] Ministry of AYUSH. Ayurveda's immunity boosting measures for self care during COVID 19 crisis. Retrieved August 11, 2020 from https://www.mohfw.gov.in/pdf/ImmunityBoostingAYUSHAdvisory.pdf.

[62] Bhawana Mittal, Trilok Chand, et al. Global Care through Ayurveda in Pandemic of COVID-19. International Journal of Health Sciences and Research, 10(6):165-172, 2020.

[63] Shankar Mondal, Saurabh Varma, Vishwa Deepak Bamola, Satya Narayan Naik, Bijay Ranjan Mirdha, Madan Mohan Padhi, Nalin Mehta, and Sushil Chandra Mahapatra. Double-blinded randomized controlled trial for immunomodulatory effects of Tulsi (Ocimum sanctum Linn.) leaf extract on healthy volunteers. Journal of Ethnopharmacology, 136(3):452-456, 2011.

[64] K. R. S. Murthy. Susruta Samhita. Varanasi, Uttar Pradesh, India: Chaukhambha Orientalia, 2008.

[65] HR Nagendra. Yoga for COVID-19. International Journal of Yoga, 13(2):87, 2020 .

[66] Amrita Nandan, Santosh Tiwari, and Vishwas Sharma. Exploring alternative medicine options for the prevention or treatment of coronavirus disease 2019 (COVID-19)-A systematic scoping review. medRxiv, 2020.

[67] Rosy Naoroibam, Kashinath G Metri, Hemant Bhargav, R Nagaratna, and HR Nagendra. Effect of Integrated Yoga (IY) on psychological states and CD4 counts of HIV-1 infected patients: A Randomized controlled pilot study. International Journal of Yoga, 9(1):57, 2016.

[68] Tanuja Manoj Nesari et al. Ayurveda: The promising shelter for the mankind in the wake of COVID-19 pandemic. Journal of Ayurveda Case Reports, 3(1):1, 2020.

[69] Li Ni, Ling Zhou, Min Zhou, Jianping Zhao, and Dao Wen Wang. Combination of western medicine and chinese traditional patent medicine in treating a family case of covid-19 in wuhan. Frontiers of medicine, pages 1-5, 2020.

[70] Liqiang Ni, Weian Yuan, Lili Chen, Chouping Han, Hong Zhang, Xin Luan, Yongfang Zhao, Jianguang Xu, and Hongzhuan Chen. Combating COVID-19 with integrated traditional Chinese and Western medicine in China. Acta Pharmaceutica Sinica B, 2020.

[71] Srivastava Niraj and Saxena Varsha. A review on scope of immuno-modulatory drugs in Ayurveda for prevention and treatment of Covid-19. Plant Science Today, 7(3):417-423, 2020. 
[72] Biplob Ozah. Triphala: A useful therapeutic supplement during COVID-19 pandemic. Journal of Drug Delivery and Therapeutics, 10(4):219-220, 2020.

[73] Ashok Kumar Panda, Amit Kumar Dixit, Suvendu Rout, Baidyanath Mishra, Umesh V Purad, and Sarbeswar Kar. Ayurveda Practitioners Consensus to Develop Strategies for Prevention and Treatment of Corona Virus Disease (COVID19). Journal of Ayurveda and Integrated Medical Sciences (ISSN 2456-3110), 5(1):98-106, 2020.

[74] Bo Pang, Junhua Zhang, Myeong Soo Lee, and Wenke Zheng. Enlightenment from clinical trials on Chinese medicine for coronavirus disease 2019 (COVID19). Integrative Medicine Research, 2020.

[75] Bhushan Patwardhan, Preeti Chavan-Gautam, Manish Gautam, Girish Tillu, Arvind Chopra, Sunil Gairola, and Suresh Jadhav. Ayurveda rasayana in prophylaxis of COVID-19. Current Science, 118:1158-1160, 2020.

[76] HM Prarthana, Sourabha S Kokatnur, and Sandeep Desai. Understanding of COVID-19 Disease Through Ayurveda. Journal of Ayurveda and Integrated Medical Sciences (ISSN 2456-3110), 5(2):169-174, 2020.

[77] Rammanohar Puthiyedath, Sushila Kataria, Unnikrishnan Payyappallimana, Prasad Mangalath, Vasudevan Nampoothiri, Pooja Sharma, Manish Kumar Singh, Kuldeep Kumar, and Naresh Trehan. Ayurvedic clinical profile of COVID19-A preliminary report. Journal of Ayurveda and Integrative Medicine, 2020.

[78] Ravi Philip Rajkumar. Ayurveda and COVID-19: Where psychoneuroimmunology and the meaning response meet. Brain, Behavior, and Immunity, 2020.

[79] Ravi Philip Rajkumar. COVID-19 and mental health: A review of the existing literature. Asian Journal of Psychiatry, page 102066, 2020.

[80] Dhirajsingh Sumersingh Rajput. Evolution, Ayurveda, immunity, and preventive aspects for emerging infectious diseases such as COVID-19. International Journal of Research in Pharmaceutical Sciences, 11(SPL1):86-93, 2020.

[81] Rajashree Ranjita, Alex Hankey, HR Nagendra, and Soubhagylaxmi Mohanty. Yoga-based pulmonary rehabilitation for the management of dyspnea in coal miners with chronic obstructive pulmonary disease: A randomized controlled trial. Journal of Ayurveda and Integrative Medicine, 7(3):158-166, 2016.

[82] Raghavendra M Rao, HR Nagendra, C Vinay Nagarathna Raghuram, S Chandrashekara, KS Gopinath, and BS Srinath. Influence of yoga on mood states, distress, quality of life and immune outcomes in early stage breast cancer patients undergoing surgery. International Journal of Yoga, 1(1):11, 2008.

[83] Sanjeev Rastogi, Deep Narayan Pandey, and Ram Harsh Singh. COVID-19 pandemic: A pragmatic plan for ayurveda intervention. Journal of Ayurveda and Integrative medicine, 2020.

[84] Preeti Rathaur, Waseem Raja, PW Ramteke, and Suchit A John. Turmeric: The Golden Spice of Life. International Journal of Pharmaceutical Sciences and Research, 3(8):1987, 2012.

[85] Shuvrodeb Roy and Pradip Bhattacharyya. Possible role of traditional medicinal plant Neem (Azadirachta indica) for the management of COVID-19 infection. International Journal of Research in Pharmaceutical Sciences, 11(SPL1):122125, 2020. 
[86] Li Runfeng, Hou Yunlong, Huang Jicheng, Pan Weiqi, Ma Qinhai, Shi Yongxia, Li Chufang, Zhao Jin, Jia Zhenhua, Jiang Haiming, et al. Lianhuaqingwen exerts anti-viral and anti-inflammatory activity against novel coronavirus (sars-cov-2). Pharmacological research, page 104761, 2020.

[87] Sandu Pharmaceuticals Ltd. Pathyadi kadha. Retrieved August 8, 2020 from http://www.sandu.in/pathyadi.html.

[88] Swami Niranjanananda Saraswati. Prana and Pranayama. Yoga Publicaitons Trust, 1 December 2009.

[89] Swami Satyananda Saraswati. Yoga Nidra. Yoga Publications Trust, Munger, Bihar, India, 2015.

[90] Chaturvedi Sarika, Kumar Nandini, Tillu Girish, Deshpande Sharad, and Patwardhan Bhushan. AYUSH, modern medicine and the Covid-19 pandemic. Indian Journal of Medical Ethics, pages 1-4, 2020.

[91] P. V. Sharma. Dravyaguna Vijnana, volume II (vegetable drugs) (Hindi). Chaukhambha Bharati Academy, Varanasi, Uttar Pradesh, India, 2001.

[92] P. V. Sharma. Caraka Samhita. Varanasi, Uttar Pradesh, India: Chaukhambha Orientalia, 2008.

[93] Parul Sharma and Ved Bhushan Sharma. Understanding of Swine Flu Through Ayurveda. Journal of Ayurveda \& Holistic Medicine (JAHM), 3(2):30-32, 2015.

[94] Swami Sharvananda. Taittiriya-Upanishad. The Ramakrishna Math, Mylapore Madras, 1921.

[95] Kunling Shen, Yonghong Yang, Tianyou Wang, Dongchi Zhao, Yi Jiang, Runming Jin, Yuejie Zheng, Baoping Xu, Zhengde Xie, Likai Lin, et al. Diagnosis, treatment, and prevention of 2019 novel coronavirus infection in children: experts' consensus statement. World journal of pediatrics, pages 1-9, 2020.

[96] Li Shi, Ying Wang, Yadong Wang, Guangcai Duan, and Haiyan Yang. Dyspnea rather than fever is a risk factor for predicting mortality in patients with COVID19. Journal of Infection, 2020.

[97] MN Shubhashree, R Naik, SH Doddamani, et al. Preventive strategies to combat infections-a review of traditional practices and Ayurveda concepts. International Journal of Complementary \& Alternate Medicine, 13(3):125-129, 2020.

[98] Awadhesh Kumar Singh, Ritesh Gupta, and Anoop Misra. Comorbidities in COVID-19: Outcomes in hypertensive cohort and controversies with renin angiotensin system blockers. Diabetes $\&$ metabolic syndrome: Clinical Research $\&$ Reviews, 2020.

[99] G. D. Singhal. Madhava-Nidana. Chaukhambha Sanskrit Pratishthan, 2016.

[100] Himesh Soni, Sarvesh Sharma, and Jitender K Malik. Synergistic Prophylaxis on COVID-19 by Nature Golden Heart (Piper betle) \& Swarna Bhasma. Asian Journal of Research in Dermatological Science, pages 21-27, 2020.

[101] Berbi Peter Stella, Sourabha S Kokatnur, and Sandeep Desai. Understanding of COVID-19 in Ayurveda and Its Managing View. Journal of Ayurveda and Integrated Medical Sciences (ISSN 2456-3110), 5(2):161-165, 2020.

[102] Chakraborty Subhrajyoti et al. Immunomodularity Herbs of Ayurveda and COVID-19: A Review Article. Journal of Ayurveda and Integrated Medical Sciences (ISSN 2456-3110), 5(2):203-208, 2020. 
[103] Chun-Yang Sun, Ya-Lei Sun, and Xin-Min Li. The role of Chinese medicine in COVID-19 pneumonia: A systematic review and meta-analysis. The American Journal of Emergency Medicine, 2020.

[104] Girish Tillu, Sarika Chaturvedi, Arvind Chopra, and Bhushan Patwardhan. Public Health Approach of Ayurveda and Yoga for COVID-19 Prophylaxis. The Journal of Alternative and Complementary Medicine, 26(5):360-364, 2020.

[105] Girish Tillu, Sundeep Salvi, and Bhushan Patwardhan. AYUSH for COVID-19 management. Journal of Ayurveda and Integrative Medicine, 11(2):95, 2020.

[106] Lance T Tomooka, Claire Murphy, and Terence M Davidson. Clinical Study and Literature Review of Nasal Irrigation. The Laryngoscope, 110(7):1189-1193, 2000 .

[107] Tong Tong, Ying-Qi Wu, Wei-Jian Ni, Ai-Zong Shen, and Sheng Liu. The potential insights of Traditional Chinese Medicine on treatment of COVID-19. Chinese Medicine, 15(1):1-6, 2020.

[108] United Nations. Resolution adopted by the General Assembly on 11 December 2014. 69/131. International Day of Yoga, January 9, 2015. Retrieved August 20, 2020 from https://en.wikisource.org/wiki/Page:United_Nations_Resolution_No._6913_(Internationa_Day_of_Yoga).djvu/1.

[109] Balachandar Vellingiri, Kaavya Jayaramayya, Mahalaxmi Iyer, Arul Narayanasamy, Vivekanandhan Govindasamy, Bupesh Giridharan, Singaravelu Ganesan, Anila Venugopal, Dhivya Venkatesan, Harsha Ganesan, et al. COVID-19: A promising cure for the global panic. Science of The Total Environment, page 138277, 2020.

[110] R. Vidyanath. Illustrated Astanga Hrdaya. Chaukhambha Sanskrit Pratishthan, 2018.

[111] Bolin Wang, Ruobao Li, Zhong Lu, and Yan Huang. Does comorbidity increase the risk of patients with COVID-19: evidence from meta-analysis. Aging (Albany NY), 12(7):6049, 2020.

[112] Zhenwei Wang, Xiaorong Chen, Yunfei Lu, Feifei Chen, and Wei Zhang. Clinical characteristics and therapeutic procedure for four cases with 2019 novel coronavirus pneumonia receiving combined chinese and western medicine treatment. Bioscience trends, 2020.

[113] Trudy M Wassenaar and Ying Zou. 2019_ncov/sars-cov-2: rapid classification of betacoronaviruses and identification of traditional chinese medicine as potential origin of zoonotic coronaviruses. Letters in Applied Microbiology, 70(5):342-348, 2020.

[114] Wikipedia. COVID-19 pandemic by country and territory. Retrieved August 28, 2020 from https://en.wikipedia.org/wiki/COVID19_pandemic_by_country_and_territory.

[115] Jiang Xie, Naima Covassin, Zhengyang Fan, Prachi Singh, Wei Gao, Guangxi Li, Tomas Kara, and Virend K Somers. Association Between Hypoxemia and Mortality in Patients with COVID-19. Mayo Clinic Proceedings, 95(6):1138$1147,2020$. 
[116] Xiao Xu, Ya-Nan Shi, Rong-Yun Wang, Ting Liu, Jingming Xu, Wen Mao, and Qiu-Hua Sun. Home-based traditional Chinese medicine nursing interventions for discharged patients with COVID-19: a rapid review of Chinese guidelines. Integrative Medicine Research, page 100479, 2020.

[117] Yang Yang, Md Sahidul Islam, Jin Wang, Yuan Li, and Xin Chen. Traditional chinese medicine in the treatment of patients infected with 2019-new coronavirus (sars-cov-2): a review and perspective. International journal of biological sciences, 16(10):1708, 2020.

[118] Lihua Zhu, Zhi-Gang She, Xu Cheng, Juan-Juan Qin, Xiao-Jing Zhang, Jingjing Cai, Fang Lei, Haitao Wang, Jing Xie, Wenxin Wang, et al. Association of Blood Glucose Control and Outcomes in Patients with COVID-19 and Pre-existing Type 2 Diabetes. Cell Metabolism, 2020. 